\section{Local Government Finance Act 1988 - Mental impairment and poll tax}

DeAr SirS

A recent 'Dear Dr' letter of 2 July 1990 reference PL/ CO(90)7 from the Department of Health by John Reed, Senior Principal Medical Officer, clarifies a few anomalies raised by me (Psychiatric Bulletin, April 1990, 14, 239-240).

The definition according to paragraph $4(3)$ of Schedule 1 to Local Government Finance Act (LGFA 1988) now is that "a person is severely mentally impaired if he has a severe impairment of intelligence and social functioning (however caused) which appears to be permanent"! It has also been recognised that the definition applies only for the purposes of LGFA 1988 and does not reflect the definition of "severe mental impairment" in the Mental Health Act (MHA 1983).

The criteria for poll tax exemption still remain the same except it has been suggested in paragraph 4 of the same 'Dear Dr' letter that the aim of the community charge is to give chargepayers a direct stake in the spending decisions of the Authority and the doctors are expected to direct the examination towards enabling them to form a view on whether the person has the capacity to understand local issues and exercise the above said stake.

One cannot understand why the term 'severe mental impairment' should be used in LGFA 1988 at all. Recognising the fact that this is going to cause confusion with the MHA 1983 is not good enough. Surely some other words like 'mental disability' could have been used and defined in the same way or rather without the clause 'social functioning', if it is expected after all that what is required to certify is the capacity to understand the local issues and exercise the person's stake in the spending decisions of the Authority.

The anomaly of differential treatment given and the clear injustice done to the people with either 'severe impairment' or 'intellectual impairment' who are cared for by relatives and friends at home would still be there unless the clause 'severe impairment of intelligence and social functioning' is replaced by 'severe impairment of intelligence and/or social functioning'.

It has also been said in paragraph 5 of this letter "that exemption from the community charge because of severe mental impairment in itself would not affect the right to vote or to be included in the electoral register". There may be different views expressed by several. I do not understand why a person should have the right to vote if he is suffering from severe mental impairment according to LGFA 1988 and the basis for diagnosis is his inability to understand the local issues and exercise his stake in the spending decisions of the Authority particularly when he is exempted from paying community charge as the community charge is intended to give the charge payer a direct stake.

Services for People

K. NADESAlingham with Mental Handicap

Church Hill House, Bracknell

Berkshire RG12 4EP

\section{References}

MetTens, J. S. (1988) 'Dear Dr' letter. Local Government Finance Act 1988 - exemption of people with severe mental impairment from liability to pay the Community Charge, Deputy Chief Medical Officer, Department of Health PL/CO(89)12, 3 November 1989.

REED, J. (1990) 'Dear Dr' letter. Local Government Finance Act 1988-exemption of people with severe mental impairment from liability to pay the Community Charge Senior Principal Medical Officer - Department of Health PL/CO(90)7, 2 July 1990.

\section{Examination of the demented patient}

\section{DeAR SIRS}

I quote from the 'Induction Course for Senior Organisers and new Examiners, Tuesday 12 September 1989' ... Seriously demented patients . . . should be excluded (from the Part I Clinical Examination)'. Thus functional illness in the elderly is a legitimate examination subject in the Part I Examination, while patients with dementia which undermines their communicative ability, are legitimate subjects in the Membership Examination. Training in psychogeriatrics is generally regarded as a proper part of training in general psychiatry. It would seem anomalous to train a junior doctor in the examination of the demented patient prior to Part I, but then maintain that such cases are too difficult to test on until the Membership Examination proper. If, therefore, the training in the demented patient is to be delayed till after Part I, then a second spell in psychogeriatric training would seem inevitable. The consequence of this would be either that psychogeriatrics would have its training split into two three-month periods, at a minimum, or that two six-month periods, at a minimum, would be allocated to this subject for people who perhaps had no intention of practising in this area in their eventual consultancy.

The College's Handbook for Inceptors and Trainees in psychiatry states (page 48) that "one of the main areas of assessment is the candidate's ability to carry out an accurate mental-state examination".... No model mental-state examination is included in the Handbook, but my guess is that Examiners expect some form of mental examination along the Adolph Meyerian model such as is found in Psychiatric Examination, a booklet emanating from the Institute of Psychiatry and the Maudsley Hospital. This book has the merit of distinguishing between the mental- 
state examination for an adult patient and that for patients over the age of 60 years. It has the further merit of including a chapter of guidance for the examination of patients with suspected, or existing, organic cerebral disease (such as would be appropriate to the Membership Examination).

I believe that the College should define when the training for the examination of the demented patient should take place and should make recommendations concerning the core mental-state examinations to be used for the elderly patient and, additionally, for the demented patient. Such recommendations would be helpful for trainees, trainers and examiners.

Warlingham Park Hospital

Carrick McDonald

Warlingham, Surrey CR3 9YR

\section{Clinical audit}

\section{Dear Sirs}

With modern trends towards various forms of audit of one's work, I would like to describe a frightening but illuminating form of a clinical audit.

Working in the field of psychiatry of old age, as a part of my job description and training I regularly attend the departmental meetings of the sister specialty of geriatric medicine. At regular intervals the following clinical audit has been performed. Case notes of a patient would be reviewed by a consultant from another team in advance of this meeting. Based on this review, the good and bad points in a variety of issues (including the history, physical examination, mental state, investigations, details of accurate documentation, discussion with relatives, timing of despatch of discharge summaries etc.) would be presented to the clinical team who had managed the patient. The audience included all the medical staff in the department, visitors like myself and the undergraduates. The clinical team would have an opportunity to respond and a detailed discussion would follow.

Superficially this exercise seemed very frightening and confrontational and there was a risk that one could lose face with one's colleagues. However in practice it appeared to be very well received and everyone found the discussion beneficial. I even began to use some of their suggestions in my psychiatric work. Exposure of the undergraduates and the junior doctors at an early stage to this form of scrutiny can only enhance the clinical and administrative skills.

It would be very interesting to use this form of clinical audit in psychiatry where very divergent use of eliciting of history and mental state and managing patients still exists. It certainly would be very educational for undergraduates and junior doctors, and it may improve working efficiency.

The Royal Free Hospital

A. K. SHaH

London NW3 2QG

\section{Request for information}

DeAR Sirs

I am coordinating a research project on behalf of a committee, which includes representatives of the Department of Health, the Health and Safety Executive and the Society of Occupational Medicine, to examine the feasibility of establishing a national register of organisations and individuals who can help with psycho-social problems in the workplace, either by counselling or providing training.

In the first instance, they will be asked to complete a questionnaire on the services they offer and the nature of their expertise.

Anyone who offers such services or has employed such services is asked to write to me within the next two months at the address below.

Hon. Secretary, OMHDG

J. F. ERSKINE

39 Westcombe Park Road

London SE3 $7 R E$

\section{Mad dog disease?}

DeAR SIRS

The beef in the freezers referred to by Dr Louis Appleby (Psychiatric Bulletin, September 1990, 14,9) may be only the tip of the iceberg. I know one 4-yearold who recently, when pressed to eat his usual favourite hot dog, exclaimed "I don't want to get mad dog disease". Is there something else we should know about!

St Edward's Hospital

Declan Murray 